\title{
Research on System of Teaching Evaluation of the Maritime Teachers Based on AHP
}

\author{
Fanyi Kong ${ }^{1, a}$, Yang Liu ${ }^{1, b}$, Xin Liü ${ }^{1, c}$, Xiuping Sui ${ }^{1, d}$ \\ ${ }^{1}$ Maritime College, Shan Dong Jiao Tong University, Wei Hai, 264200, China \\ akfy2006@yeah.net, ${ }^{b}$ bgodkissyou@126.com, ${ }^{\text {c }}$ caxinzaixian@163.com, ${ }^{\text {d }}$ sui xiuping@126.com
}

Keywords: Maritime teacher, Teaching Ability, Evaluation, AHP.

\begin{abstract}
Maritime teaching is to a special professional education in higher education. The teaching ability of maritime teachers' is directly related to the future of student's professional level. And it is of great significance for navigation class education. But the teaching ability evaluation of many maritime colleges' teachers is subjective without using a simple and scientific method so that their weights aren't established. In the paper, using Analytic Hierarchy Process (AHP), we study with related factors of teaching of maritime teachers and determine the relevant indicators of this evaluation with applying science and reasonable method to evaluate, thus we establish the System of Teaching Evaluation of the Maritime Teachers.
\end{abstract}

\section{Introduction}

With the development of shipping industry, China shipping companies are stepping onto the top of the world stage, but the competition is becoming more and more competition. Especially, China's economy is facing the impact of the international financial crisis so that it is already too great challenges for shipping with shipping enterprises in China facing pressure from the external and internal environment. Nowadays China has become the world's largest exporter of seafarers, therefore the maritime teaching quality problem has been gained by the wide attention of Marine industry. Our country's higher navigation education is to accept the supervision and management by the ministries of education and maritime administration. So the teaching plan should not only meet the requirements of the national academic education, but also need to meet the provisions of the STCW convention and maritime authorities. Maritime colleges and universities, therefore, must establish and implement the correct system of the quality management, and in the case of running efficiently the system, we could guarantee the quality of navigation class teaching so as to ensure the quality of maritime graduates.

In the navigation teaching, teachers' teaching level is one of important indicators to measure teaching quality of the maritime college. And it can directly affect the success of shipping talented person's training work. Therefore, teaching quality evaluation of navigation teachers will be one of the main means in order to guarantee and improve the teaching quality of maritime colleges, so this is a very worthy of study and practice. For maritime teachers teaching evaluation, it should be scientific, comprehensive and fair reflected the real level of teaching to good guide role for the teaching. However, most of the maritime teaching quality evaluation are started from analyzing their qualitative factors at present, and used for combining college's leaders and teams evaluation and student evaluation. Application of fuzzy judgment based on AHP model in the evaluation of teaching quality and The model of teaching evaluation index based on AHP and the other relevant articles are not basic on the maritime teachers teaching evaluation. In this research, the current domestic research is relatively small. So this paper considers the comprehensive maritime teachers teaching related factors using analytic hierarchy process (AHP), and determines the evaluation of the relevant indicators, which applied science and reasonable method to evaluate, thus establishes System of Teaching Evaluation of the Maritime Teachers. 


\section{The basic steps of application of AHP}

\section{Establish judgment matrix}

According to the practical problems, we can establish the hierarchical structure, then the Judgment matrix is gained. Judgment matrix refers to the matrix which reflects the various indexes of the same level factors influence with the upper indexes, and adopts the quantitative method. Then the final results are obtained by comparing with the importance of every index in the same level, and they will be stowed in the corresponding position in the matrix. The comparison of paired index, the estimate of the relative importance of the index $j$ to the index $i$ is recorded for $a_{i j}$, according to the provisions of the values in table $1 .[1,2]$

Table 1 the values method of element $a_{i j}$

\begin{tabular}{|c|c|}
\hline Intensity & Explanation \\
\hline 1 & Two factors contribute equally to the objective \\
\hline 3 & Experience and judgment favor one factor over another \\
\hline 5 & An factor is strongly favored and its dominance demonstrated in practice \\
\hline 7 & $\begin{array}{c}\text { The evidence of favoring one factor over another is of the highest possible order of } \\
\text { affirmation }\end{array}$ \\
\hline $2,4,6,8$ & Intermediate values when compromise is needed \\
\hline reciprocal & $\begin{array}{c}\text { If the ratio of importance of factors } i \text { and } j \text { to } a_{i j} \text { then the ratio of importance of factors } i \\
\text { and } j \text { to } a_{j i}=1 / a_{i j}\end{array}$ \\
\hline
\end{tabular}

According to table 1, building the form of matrix, that is the judgment matrix, that is,

$\mathrm{A}=\left[\begin{array}{cccc}a_{11} & a_{12} & \cdots & a_{1 n} \\ a_{21} & a_{22} & \cdots & a_{21} \\ \vdots & \vdots & \vdots & \vdots \\ a_{n 1} & a_{n 2} & \cdots & a_{n 4}\end{array}\right]$. If there is $a_{i j}=1$, Two factors of $A_{i}$ and $A_{j}$ contribute equally to the objective, that is, Weight values are equal. If there is $a_{i j}>1, A_{i}$ is more important than $A_{j}$. If there is $a_{i j}<1, A_{i}$ is not more important than $A_{j}$. According to the above characteristics, there is $a_{j i}=1 / a_{i j}$ so that judgment matrix $A$ is positive reciprocal matrix.

\section{Calculate the weight value of index}

Set on a certain criterion, the weight vector of each index for the equation (1), which is

$W=W\left(W_{1}, W_{2}, \cdots, W_{n}\right)^{T}$.

Therefore, $W$ can be obtained by solving the following equation(2),

$A W=\lambda_{\max } W$

In the equation (2), $\lambda_{\max }$ is to the largest eigenvalue of the judgment matrix A.

The accurate of each index weight value can be calculated by the following process,

i. Calculate the product of each line elements of judgment matrix A to obtain the $M_{i}$, that is,

$M_{i}=\prod_{j=1}^{n} a_{i j}(i, j=1,2, \cdots, n)$

ii. Calculate the Nth root of $M_{i}$ that is $\bar{W}_{i}$.

$\bar{W}_{i}=\sqrt[n]{M_{i}}$

iii. The Vector is $\bar{W}=\left(\bar{W}_{1}, \bar{W}_{2}, \cdots, \bar{W}_{n}\right)^{T}$ which will be of the normalization processing, that is,

$W_{i}=\bar{W}_{i} / \sum_{i=1}^{n} \bar{W}_{j}(i, j=1,2, \cdots, n)$

So Vector $\bar{W}=\left(\bar{W}_{1}, \bar{W}_{2}, \cdots, \bar{W}_{n}\right)^{T}$ is obtained to ask the weight vector.

iv. Calculate the maximum eigenvalue of judgment matrix $A$

$\lambda_{\max }=\frac{1}{n} \sum_{\mathrm{i}=1}^{n}(A W)_{i} / W_{i}$ 
$(A W)_{i}$ stands for the ith element of vector $A W$ in the formula.

\section{Check the consistency}

Because policy makers knowing the question is not comprehensive and the decision problem is be of complexity, judgment matrix A can not be of the consistent, especially when the deviation of consistency is too large, it will cause problems. After getting the $\lambda_{\max }$, we also must carry out checking consistency of judgment matrix A and calculate the consistency index $C I$ and relative consistency index $C R$, the following of calculation process, such as formula $C I=\frac{\lambda_{\max }-n}{n-1}$ (7) and $C R=\frac{C I}{R I}(8)$.

$R I$ stands for the average consistency index which is the calculation according to more than enough random judgment matrices, as shown in table 2.[3,4]

Table 2 the average consistency index

\begin{tabular}{|c|c|c|c|c|c|c|c|c|c|c|}
\hline order of the matrix & 1 & 2 & 3 & 4 & 5 & 6 & 7 & 8 & 9 & 10 \\
\hline RI & 0 & 0 & 0.58 & 0.9 & 1.12 & 1.24 & 1.32 & 1.41 & 1.45 & 1.49 \\
\hline
\end{tabular}

The consistency of judgment matrix $\mathrm{A}$ is associated with $C R$, and the smaller the $C R$, the better judgment. Generally if there is $C R \leq 0.1$, the judgment matrix A has a good consistency, that is, the characteristic vectors of each index weight can be applied.

Table 3 The hierarchy chart of teaching evaluation index of maritime teachers

\begin{tabular}{|c|c|c|}
\hline & Primary indexes & Secondary indexes \\
\hline \multirow{28}{*}{$\begin{array}{l}\text { Teaching } \\
\text { Capability } \\
\text { of } \\
\text { Maritime } \\
\text { Teachers } \\
\quad \text { (A0) }\end{array}$} & \multirow{5}{*}{$\begin{array}{c}\text { moral level and } \\
\text { nautical literacy } \\
\text { of maritime } \\
\text { teachers (A1) }\end{array}$} & political attitude and thinking consciousness of maritime teachers(A11) \\
\hline & & moral cultivation and behavior of maritime teachers(A12) \\
\hline & & cognitive ability about own role of maritime teachers(A13) \\
\hline & & knowing the navigational capabilities of maritime teachers(A14) \\
\hline & & $\begin{array}{c}\text { understanding the development prospects and direction of navigation } \\
\text { professional (A15) }\end{array}$ \\
\hline & \multirow{5}{*}{$\begin{array}{l}\text { course design } \\
\text { capacity of } \\
\text { maritime } \\
\text { teachers (A2) }\end{array}$} & locating capability for maritime course(A21) \\
\hline & & the combination of practice and class ability of maritime teachers(A22) \\
\hline & & designed capacity of maritime curriculum program(A23) \\
\hline & & $\begin{array}{c}\text { capability of development and utilization of maritime curriculum } \\
\text { resources(A24) }\end{array}$ \\
\hline & & capability of reform and innovation about maritime courses(A25) \\
\hline & \multirow{5}{*}{$\begin{array}{l}\text { teaching design } \\
\text { and } \\
\text { implementation } \\
\text { capacity of } \\
\text { maritime } \\
\text { teachers (A3) }\end{array}$} & capability of practice demonstration of maritime teachers(A31) \\
\hline & & $\begin{array}{c}\text { capability of class's organization and management of maritime } \\
\text { teachers(A32) }\end{array}$ \\
\hline & & capability of language expression of maritime teachers(A33) \\
\hline & & capability of guiding the student of maritime teachers(A34) \\
\hline & & capability of teaching innovation method of maritime teacher(A35) \\
\hline & \multirow{5}{*}{$\begin{array}{c}\text { students' } \\
\text { learning and } \\
\text { understanding } \\
\text { ability in the } \\
\text { maritime } \\
\text { classroom (A4) }\end{array}$} & Grasping the ability of the maritime students' learning psychology(A41) \\
\hline & & Familiar with the maritime students' having their ability(A42) \\
\hline & & Grasping the ability of students' understanding maritime knowledge(A43) \\
\hline & & $\begin{array}{c}\text { Familiar with the laws of maritime students' intelligence } \\
\text { development(A44) }\end{array}$ \\
\hline & & Grasping the ability of the maritime students' mental health(A45) \\
\hline & \multirow{4}{*}{$\begin{array}{c}\text { teaching } \\
\text { reflection and } \\
\text { evaluation } \\
\text { capacity of } \\
\text { maritime } \\
\text { teachers (A5) }\end{array}$} & $\begin{array}{l}\text { implementation capacity of the teaching evaluation of maritime teachers } \\
\text { (A51) }\end{array}$ \\
\hline & & designed capacity of the teaching evaluation of maritime teachers (A52) \\
\hline & & reformed capacity of the teaching evaluation of maritime teachers(A53) \\
\hline & & Ability of applying a variety of methods for teaching evaluation(A54) \\
\hline & \multirow{4}{*}{$\begin{array}{l}\text { academic } \\
\text { research and } \\
\text { application } \\
\text { capacity of } \\
\text { maritime } \\
\text { teachers (A6) }\end{array}$} & capability of publishing papers, and works of maritime teachers(A61) \\
\hline & & capability of research of maritime teachers(A62) \\
\hline & & $\begin{array}{l}\text { capability of using new technology to promote teaching for maritime } \\
\text { teachers(A63) }\end{array}$ \\
\hline & & capability of promoting the development of maritime students(A64) \\
\hline
\end{tabular}




\section{The specific application of AHP in System of Teaching Evaluation of the Maritime Teachers}

\section{Establish the index system of Teaching Evaluation of the Maritime Teachers}

According to the current used index of teaching evaluation of teachers in many maritime colleges, this paper mainly will establish index system of teaching evaluation of the maritime teachers from the following six aspects which are A1, A2, A3, A4, A5 and A6. In this paper, according to the AHP, it will establish a structure model of three level layers that is shown in table 3.

\section{Establish the judgment matrix}

This paper will compare between any two in each layer of the index system of teaching evaluation of the maritime teachers so that the different judgment matrix are constructed respectively.

Establish the judgment matrix A in the primary index layer, as shown in table 4.

Table 4 judgment matrix A

\begin{tabular}{|c|c|c|c|c|c|c|}
\hline A0 & A1 & A2 & A3 & A4 & A5 & A6 \\
\hline A1 & 1.0000 & 2.0000 & 4.0000 & 3.0000 & 4.0000 & 5.0000 \\
\hline A2 & 0.5000 & 1.0000 & 2.0000 & 1.0000 & 2.0000 & 2.0000 \\
\hline A3 & 0.2500 & 0.5000 & 1.0000 & 1.0000 & 1.0000 & 1.0000 \\
\hline A4 & 0.3333 & 1.0000 & 1.0000 & 1.0000 & 1.0000 & 2.0000 \\
\hline A5 & 0.2500 & 0.5000 & 1.0000 & 1.0000 & 1.0000 & 1.0000 \\
\hline A6 & 0.2000 & 0.5000 & 1.0000 & 0.5000 & 1.0000 & 1.0000 \\
\hline
\end{tabular}

Similarly, the method of establishing judgment matrix A can be used for building the matrices A1, A2, A3, A4, A5, A6 such as table5, table 6 and table 7 and table 8, table 9 and table10.

Table 5 judgment matrix A1

\begin{tabular}{|l|l|l|l|l|l|}
\hline A1 & A11 & A12 & A13 & A14 & A15 \\
\hline A11 & 1.0000 & 3.0000 & 3.0000 & 2.0000 & 2.0000 \\
\hline A12 & 0.3333 & 1.0000 & 1.0000 & 0.5000 & 0.5000 \\
\hline A13 & 0.3333 & 1.0000 & 1.0000 & 0.5000 & 0.5000 \\
\hline A14 & 0.5000 & 2.0000 & 2.0000 & 1.0000 & 1.0000 \\
\hline A15 & 0.5000 & 2.0000 & 2.0000 & 1.0000 & 1.0000 \\
\hline
\end{tabular}

Table 6 judgment matrix A2

\begin{tabular}{|l|l|l|l|l|l|}
\hline A2 & A21 & A22 & A23 & A24 & A25 \\
\hline A21 & 1.0000 & 2.0000 & 3.0000 & 3.0000 & 2.0000 \\
\hline A22 & 0.5000 & 1.0000 & 2.0000 & 2.0000 & 1.0000 \\
\hline A23 & 0.3333 & 0.5000 & 1.0000 & 1.0000 & 0.5000 \\
\hline A24 & 0.3333 & 0.5000 & 1.0000 & 1.0000 & 0.5000 \\
\hline A25 & 0.5000 & 1.0000 & 2.0000 & 2.0000 & 1.0000 \\
\hline
\end{tabular}

Table 7 judgment matrix A3

\begin{tabular}{|l|l|l|l|l|l|}
\hline A3 & A31 & A32 & A33 & A34 & A35 \\
\hline A31 & 1.0000 & 3.0000 & 2.0000 & 3.0000 & 1.0000 \\
\hline A32 & 0.3333 & 1.0000 & 0.5000 & 1.0000 & 0.2500 \\
\hline A33 & 0.5000 & 2.0000 & 1.0000 & 2.0000 & 0.5000 \\
\hline A34 & 0.3333 & 1.0000 & 0.5000 & 1.0000 & 0.3333 \\
\hline A35 & 1.0000 & 0.2500 & 2.0000 & 0.3333 & 1.0000 \\
\hline
\end{tabular}

Table 8 judgment matrix A4

\begin{tabular}{|l|l|l|l|l|l|}
\hline A4 & A41 & A42 & A43 & A44 & A45 \\
\hline A41 & 1.0000 & 0.5000 & 0.2000 & 0.3333 & 0.2500 \\
\hline A42 & 2.0000 & 1.0000 & 0.4000 & 0.8889 & 0.5000 \\
\hline A43 & 5.0000 & 2.4500 & 1.0000 & 1.8889 & 1.2500 \\
\hline A44 & 0.3333 & 1.5000 & 0.6000 & 1.0000 & 0.7500 \\
\hline A45 & 4.0000 & 2.0000 & 0.8000 & 1.3333 & 1.0000 \\
\hline
\end{tabular}


Table 9 judgment matrix A5

\begin{tabular}{|l|l|l|l|l|}
\hline A5 & A51 & A52 & A53 & A54 \\
\hline A51 & 1.0000 & 0.3333 & 0.5000 & 0.5000 \\
\hline A52 & 3.0000 & 1.0000 & 2.0000 & 2.0000 \\
\hline A53 & 2.0000 & 0.5000 & 1.0000 & 1.0000 \\
\hline A54 & 2.0000 & 0.5000 & 1.0000 & 1.0000 \\
\hline
\end{tabular}

Table 10 judgment matrix A6

\begin{tabular}{|l|l|l|l|l|}
\hline A6 & A61 & A62 & A63 & A64 \\
\hline A61 & 1.0000 & 0.5000 & 0.3333 & 0.5000 \\
\hline A62 & 2.0000 & 1.0000 & 0.5000 & 1.0000 \\
\hline A63 & 3.0000 & 2.0000 & 1.0000 & 2.0000 \\
\hline A64 & 2.0000 & 1.0000 & 0.5000 & 1.0000 \\
\hline
\end{tabular}

\section{Calculate the weight value of each index}

For the index system of teaching evaluation of the maritime teachers, this paper firstly calculate the weight value of the primary index value, such as judgment matrix A, according to the instruction of second part, which would get the weight vector, that is, $\mathrm{W}=(0.39560 .17970 .10100 .13550 .10100$. 0868).Thus, the vector $W$ is weight values of $A 1, \ldots, A 6$ in at the sub-system of goal layer. In other words, the ratio of the moral level and nautical literacy of maritime teacher in the index system of teaching evaluation of the maritime teachers is $39.56 \%$, that is, the weight value is 0.3956 . Similarly, we can get the other weights.

By the same calculation method, the weight value of the secondary index can be calculated.

$\mathrm{A} 1: \mathrm{W}(1)=(0.36860 .10950 .10950 .20660 .2066)$,

$\mathrm{A} 2: \mathrm{W}(2)=(0.36860 .20660 .10950 .10950 .2066)$,

$\mathrm{A} 3: \mathrm{W}(3)=(0.30910 .09220 .17360 .09760 .3275)$,

$\mathrm{A} 4: \mathrm{W}(4)=(0.06680 .13330 .33330 .20000 .2668)$,

$\mathrm{A} 5: \mathrm{W}(5)=(0.12250 .42310 .22720 .2272), \mathrm{A6}: \mathrm{W}(6)=(0.12250 .22720 .42310 .2272)$.

\section{Check the consistency of every index}

In order to check the consistency of judgment matrix, the maximum eigenvalue of judgment matrix firstly can be calculated. Here it is the example of judgment matrix A. Due to the judgment matrix A, weight vector and formula (6), the result which is $\lambda=6.0682$ can be obtained by using the Matlab. Followed by the formula (7), which is $C I=\frac{\lambda_{\max }-n}{n-1}$, the consistency index CI of judgment matrix A can be concluded, which is $\mathrm{CI}=0.0136$.

Finally, the ratio between CI and random consistency index RI of judgment matrix with the same rank is calculated, and this ratio stands for $\mathrm{CR}$, which the value of $\mathrm{RI}$ can be checked by table 2.By the formula (8), $\mathrm{CR}=0.0110$ can be calculated. It can be seen that $\mathrm{CR}<0.1$ so as to pass checking consistency of the primary index.

In the same way, the checking consistency of the secondary indexes also can be validated.

$\mathrm{A} 1: \lambda=5.0135, \mathrm{CI}=0.0034, \mathrm{CR}=0.0030<0.1, \mathrm{~A} 2: \lambda=5.0135, \mathrm{CI}=0.0034, \mathrm{CR}=0.0030<0.1$. $\mathrm{A} 3: \lambda=5.0163, \mathrm{CI}=0.0041, \mathrm{CR}=0.0037<0.1, \mathrm{~A} 4: \lambda=5.0003, \mathrm{CI}=0.0001, \mathrm{CR}=0.0000<0.1$. $\mathrm{A} 5: \lambda=4.0105, \mathrm{CI}=0.0035, \mathrm{CR}=0.0039<0.1, \mathrm{~A} 6: \lambda=4.0103, \mathrm{CI}=0.0034, \mathrm{CR}=0.0038<0.1$.

By the above values of the $\mathrm{CR}$, the consistency all secondary index can be passed.

\section{Calculate the teaching evaluation value of the maritime teachers}

The above index weight values are calculated in the weights of index layer. So in order to refine the secondary indexes, the final evaluation results of teaching capability of the maritime teachers can be calculated, the secondary indexes weight values in the primary index layer will be change into absolute weight values in the goal layer(Teaching capability of the Maritime Teachers).The calculation method is that each component value of the corresponding vector W(i) of the judgment matrices A1,... , A6 in the secondary index layer will be multiplied by corresponding weight value matrix in the primary index layer, so the calculation is W(i)'which is the final absolute weights in the secondary 
index layer.For example, the following judgment matrix A1, that is,A1:A(1) ${ }^{\prime}=(0.36860 .10950$. $10950.20660 .2066) * 0.3956=\left(\begin{array}{ll}0.1458 & 0.04330 .04330 .08170 .0817\end{array}\right)$.

Thus it can be seen that the weight value of political attitude and thinking consciousness of maritime teachers in the secondary indexes is of 0.1458 in the whole index system of teaching evaluation of the maritime teachers. Using the same way, each absolute weight values can be concluded in the secondary index.

In conclusion, the maritime teachers' teaching integrated evaluation can be calculated by $\sum_{i=1}^{n} p(i)^{*} W(i)^{\prime}$ which consist of $p(i)$ (the value of the child i indicators) and $W(i)^{\prime}$ (the absolute weight of the child I index in the teaching ability of maritime teachers). $p$ (i)can take on any arbitrary a value of $0 \sim 100$. Finally, teaching evaluation's score of maritime teachers is between $0 \sim 100$. Then maritime teachers 'teaching ability can be judged through the comparison of digital.

\section{Summary}

Analytic Hierarchy Process (AHP) is one of the research method of the System of Teaching Evaluation of the Maritime Teachers. It is good for many factors of which teaching evaluation of the maritime teachers has an impact to consider as a whole system. It gives priority with the quantitative methods, and the qualitative is complementary. Thus the teaching ability score of maritime teachers is calculated. Compared with previous qualitative evaluation methods, it can overcome the deficiencies of some traditional methods and objectively reflect the teaching ability of maritime teachers. However, limited by the level of researchers and experts' subjectivity in evaluation system, the applicability of the system of teaching evaluation of the maritime teachers remains to be further tested. But the method for upgrading and innovation with the maritime colleges and universities teachers' teaching ability has a distinct role.

\section{Acknowledgements}

This work was financially supported by the Project of Shandong Jiaotong University Natural Science Foundation(No: Z201334).

\section{References}

[1] WU Shuqin.The Application of AHP in Construction of Competency Model for University Recruitment. Science and Technology Management Research.3(2011) 60-66.

[2] ZHAO Chun- yuan. Application of fuzzy judgment based on AHP model in the evaluation of teaching quality. Journal of Shenyang Institute of Engineering( Natural Science).7.2(2011)116-122.

[3] Xie Jian,Chu Dan, Ge Han. Research on System of Teaching Evaluation of Teachers in Colleges Based on AHP[J].China Adult Education.4(2015)96-101.

[4] Wei Wei, Han Jianhua, Wen Jikui.Evaluating Education Technology Ability of Teachers in Higher Education Based on AHP And CA.JOURNAL OF BEIJING INST TUTE OF EDUCATION NATURAL SCIENCE EDITION.3(2015)61-69. 